\title{
Effects of Buffer Loading for Electrospray Ionization Mass Spectrometry of a Noncovalent Protein Complex that Requires High Concentrations of Essential Salts
}

\author{
Harry J. Sterling, Joseph D. Batchelor, David E. Wemmer, and \\ Evan R. Williams \\ Department of Chemistry, University of California-Berkeley, Berkeley, California, USA
}

\begin{abstract}
Electrospray ionization (ESI) mass spectrometry (MS) is a powerful method for analyzing the active forms of macromolecular complexes of biomolecules. However, these solutions often contain high concentrations of salts and/or detergents that adversely effect ESI performance by making ion formation less reproducible, causing severe adduction or ion suppression. Many methods for separating complexes from nonvolatile additives are routinely used with ESI-MS, but these methods may not be appropriate for complexes that require such stabilizers for activity. Here, the effects of buffer loading using concentrations of ammonium acetate ranging from 0.22 to 1.41 $\mathrm{M}$ on the ESI mass spectra of a solution containing a domain truncation mutant of a $\sigma^{54}$ activator from Aquifex aeolicus were studied. This $44.9 \mathrm{kDa}$ protein requires the presence of millimolar concentrations of $\mathrm{Mg}^{2+}, \mathrm{BeF}_{3}{ }^{-}$, and ADP, (at $\sim 60^{\circ} \mathrm{C}$ ) to assemble into an active homo-hexamer. Addition of ammonium acetate can improve signal stability and reproducibility, and can significantly lower adduction and background signals. However, at higher concentrations, the relative ion abundance of the hexamer is diminished, while that of the constituent monomer is enhanced. These results are consistent with loss of enzymatic activity as measured by ATP hydrolysis and indicate that the high concentration of ammonium acetate interferes with assembly of the hexamer. This shows that buffer loading with ammonium acetate is effective for obtaining ESI signal for complexes that require high concentrations of essential salts, but can interfere with formation of, and/or destabilize complexes by disrupting crucial electrostatic interactions at high concentration. (J Am Soc Mass Spectrom 2010, 21, 1045-1049) (c) 2010 Published by Elsevier Inc. on behalf of American Society for Mass Spectrometry
\end{abstract}

$\mathrm{E}$ lectrospray ionization mass spectrometry (ESIMS) is an important technique for studying intact noncovalent complexes of biomolecules, owing to its capacity to provide information about stoichiometries [1], binding interfaces [2], relative [3, 4], and absolute [5] equilibrium constants, conformations [6], and assembly kinetics [7], with high sensitivity, speed, and specificity. An important factor in the ability to obtain high quality mass spectra is the compatibility of the analyte complex with the solvent systems typically employed in ESI-MS, i.e., aqueous ammonium acetate or ammonium bicarbonate solutions with minimal nonvolatile salts or detergents. Nonvolatile salts and detergents, often used to stabilize biomolecule complexes, are typically removed by buffer exchange into solutions of ammonium acetate or ammonium bicarbonate using microcentrifuge gel-filtration columns or dialysis before analysis [8]. Even low millimolar concentrations of metal ion salts, such as sodium chloride or phosphate,

Address reprint requests to Professor E. R. Williams, Department of Chemistry, University of California, Berkeley, Berkeley, CA 94720, USA. E-mail: williams@cchem.berkeley.edu can cause severe ion suppression and peak broadening due to cluster and adduct formation. However, the roles of specific ions are well known for many noncovalent complexes of proteins with other proteins [9], peptides [10], nucleic acids [11], small molecules [12], cations [13], anions [14], nucleotides [15], etc., and the presence of these ions in the analyte solution can therefore be essential to obtain an accurate measurement of the native or native-like state of the complex. Other biophysical techniques used to study noncovalent complexes, such as native gel electrophoresis, small angle X-ray scattering, NMR, electron microscopy, and analytical ultracentrifugation are not compromised by the presence of metal ion salts.

Both desorption electrospray ionization [16] and matrixassisted laser desorption ionization [17] are less affected by salts than ESI. Nonetheless, several approaches that make it possible to more readily electrospray from solutions containing metal ion salts and biomolecules have been developed. Konermann and coworkers used tartrate anions as weak chelators to minimize nonspecific adduction in ESI-MS studies of $\mathrm{Ca}^{2+}$ and $\mathrm{Zn}^{2+}$ binding proteins [18]. In an ESI-MS based enzymatic 
activity assay of cAMP-dependent protein kinase A, addition of methanol and acetic acid was shown to improve detection of phosphopeptides from solutions that required micromolar concentrations of cAMP, $\mathrm{Mg}^{2+}$, and ATP [19]. High concentrations of a volatile buffer can dramatically reduce the adverse effects of salts in ESI [20]. Addition of up to $7 \mathrm{M}$ ammonium acetate to solutions containing $20 \mathrm{mM}$ sodium chloride, and either cytochrome $c$ or ubiquitin, resulted in a $\sim 7$ and 11-fold improvement in signal-to-noise for these respective proteins [20]. This buffer loading technique [20] was shown to be effective for a noncovalent protein complex by Hernandez and Robinson [8], who demonstrated significantly improved resolution for the $\sim 150$ $\mathrm{kDa}$ tetramer of alcohol dehydrogenase with $1 \mathrm{M}$ ammonium acetate solutions that contained this protein and either $10 \mathrm{mM}$ Tris-HCL or $10 \mathrm{mM}$ HEPES. Buffer loading with $1 \mathrm{M}$ ammonium acetate was used to obtain mass spectra of different oligomeric states of wild-type and mutant DnaB and DnaC proteins from Escherichia coli, which require up to 0.1 and $1.0 \mathrm{mM} \mathrm{ATP}$ and $\mathrm{Mg}(\mathrm{OAc})_{2}$, respectively, to assemble [21]. However, the stabilities of many complexes can depend on both ionic strength and specific ionic cofactors [22-27], so this buffer loading method is most effective when the salt tolerance of the complex is known.

Here, effects of ammonium acetate concentration on ESI mass spectral resolution and complex stability of a domain truncation mutant of a $\sigma^{54}$ activator (NtrC4-RC) from the thermophilic bacterium Aquifex aeolicus, which requires millimolar concentrations of $\mathrm{Mg}^{2+}, \mathrm{BeF}_{3}{ }^{-}$, and ADP (at $\sim 60{ }^{\circ} \mathrm{C}$ ) for assembly into a $\sim 270 \mathrm{kDa}$ homohexamer [28, 29], are investigated. This truncated form of the full-length NtrC4 protein was chosen because it is somewhat more soluble than the full length protein and activation with the essential salts induces a change in the stoichiometries of the observed complexes from mixed homo-oligomers with no ATPase activity to a hexamer with similar ATPase activity to that of the full-length protein [29]. A spectrophotometric ATPase activity assay [30] of the hexamer was used to independently measure the effects of ammonium acetate concentration on the abundance of the functional form of this complex. At lower concentrations, ammonium acetate can increase the stability, reproducibility, and accuracy for measuring the mass and abundance of this noncovalent complex in solution, but at higher concentrations, it can interfere with assembly of the complex, presumably by displacement and/or interference of the critical electrostatic interactions with the essential salts.

\section{Experimental}

\section{Protein Expression and Purification}

Protein expression and purification are described in detail elsewhere [29]. Briefly, NtrC4-RC was subcloned into a PSKB3 plasmid with a $\mathrm{His}_{6}$ tag, expressed in E. coli. BL21 (DE3), harvested by sonication, and puri- fied with a Ni-agarose column. The plasmid was sequenced at the University of California at Berkeley DNA sequencing facility.

\section{Mass Spectrometry}

Mass spectra were acquired using a quadrupole timeof-flight mass spectrometer equipped with a Z-spray ion source (Q-TOF Premier; Waters, Milford, MA, USA). Ions were formed using nanoelectrospray emitters prepared by pulling borosilicate capillaries $(1.0 \mathrm{~mm}$ o.d./0.78 mm i.d.; Sutter Instruments, Novato, CA, USA) to a tip i.d. of $\sim 1 \mu \mathrm{m}$ with a Flaming/Brown micropipette puller (model P-87, Sutter). A platinum wire (0.127 $\mathrm{mm}$ diameter, Sigma, St. Louis, MO, USA) was inserted through the capillary into the solution and electrospray was initiated and maintained by applying $\sim 1 \mathrm{kV}$ to the wire relative to instrument ground. This voltage was adjusted to the lowest value at which ion current was stable. All other instrument parameters, including the source backing pressure (5.9 Torr), were the same for all experiments. The solutions were heated before and during data acquisition using a capillary heater described elsewhere [31]. The temperature of the capillary heater was monitored continuously with a thermocouple and temperature meter (Omega, Stamford, CT, USA). Raw data were smoothed three times using the Waters MassLynx software mean smoothing algorithm with a 75 unit window. Average molecular masses were obtained by deconvolution of the centroids of each peak in a given charge state distribution with a signal-to-noise $>\sim 3$, and those for the hexamer were corrected for non-specific adduction by the method of McKay et al. [32]. Relative abundances of proteins and complexes were estimated by summing the intensities of each charge state of a given protein or protein complex, and dividing that value by the sum of the intensities for each charge state in the distributions of monomer + dimer + hexamer. This does not take into account effects of mass dependent ion transfer or detection efficiency or ionization efficiency. Thus, the trends in these relative abundances as a function of ammonium acetate concentration are more meaningful than the actual absolute values. The instrument was calibrated with CsI clusters formed by nano-ESI of a 24 $\mathrm{mg} / \mathrm{mL}$ solution of CsI in 70:30 Milli-Q:2-propanol before mass measurement.

\section{ATPase Activity Assays}

Individual $14.5 \mu \mathrm{L}$ samples of NtrC4-RC in the presence of $\mathrm{MgCl}_{2}, \mathrm{BeCl}_{2}, \mathrm{NaF}$, and various concentrations of ammonium acetate were incubated at $70{ }^{\circ} \mathrm{C}$ for $5 \mathrm{~min}$. Then, $0.5 \mu \mathrm{L}$ of $30 \mathrm{mM}$ ATP was added to each sample, bringing the final reaction concentrations to $50 \mu \mathrm{M}$ NtrC4-RC, $1 \mathrm{mM}$ ATP , $1 \mathrm{mM} \mathrm{MgCl}, 1 \mathrm{mM} \mathrm{BeCl} 2,9 \mathrm{mM}$ $\mathrm{NaF}$, and either $0.22,0.34,0.45,0.68,0.95,1.14$, or $1.41 \mathrm{M}$ ammonium acetate. At various time points, $3 \mu \mathrm{L}$ aliquots were quenched with $350 \mu \mathrm{L}$ of $0.88 \mathrm{M} \mathrm{HNO}_{3}$. A 
color-developing solution $(400 \mu \mathrm{L})$ consisting of $44 \mu \mathrm{M}$ $\mathrm{Bi}\left(\mathrm{NO}_{3}\right)_{2}, 31.1 \mu \mathrm{M}\left(\mathrm{NH}_{4}\right)_{6} \mathrm{Mo}_{7} \mathrm{O}_{24}$, and $0.11 \%$ ascorbic acid was added to the quenched reactions. Exactly 4 min after the addition of color-developing solution, the amount of free phosphate in solution (a product of ATP hydrolysis) was measured using the absorbance of 700 $\mathrm{nm}$ light, which is proportional to phosphate concentration [30]. These absorbance measurements were obtained for multiple time points and used to calculate $\mathrm{k}_{\mathrm{cat}}$, the moles of ATP hydrolyzed per mole of protein per minute. Measurement of $\mathrm{k}_{\text {cat }}$ at each buffer concentration was performed in triplicate, and the averaged results, with error bars representing one standard deviation, are shown in Figure $1 b$.

\section{Results and Discussion}

ESI mass spectra obtained from solutions that contained $25 \mu \mathrm{M}$ protein monomer, $1 \mathrm{mM}$ ADP, $5 \mathrm{mM} \mathrm{MgCl}_{2}, 1$ $\mathrm{mM} \mathrm{BeCl}, 9 \mathrm{mM} \mathrm{NaF}$, and seven different concentrations of ammonium acetate, ranging from 0.22 to 1.41 $\mathrm{M}$, are shown in Figure $1 \mathrm{a} . \mathrm{BeF}_{3}{ }^{-}$, which mimics phosphorylation, is formed from $1 \mathrm{mM} \mathrm{BeCl}_{2}$ as the limiting reagent and $9 \mathrm{mM} \mathrm{NaF}$ in excess. These solu- tions were heated to $63{ }^{\circ} \mathrm{C}$ before, and during, the experiments. The presence of the salts and nucleotide, and the elevated temperature, are required for a conformational change in the regulatory domain of the monomer that makes it possible for the protein to assemble into a hexamer [29]. Without the salts, nucleotide, and heat, this domain truncation mutant assembles into a heptamer and other mixed oligomers, whereas the stoichiometry of the complex composed of the native, full-length protein is a hexamer [29]. Three replicate spectra of each solution, each acquired using a different nanoelectrospray capillary, were measured and the spectra in Figure 1a were selected from the replicates as a typical spectrum with respect to peak centroids, widths, and relative abundances. Signal at the two lowest ammonium acetate concentrations was significantly less reproducible than at the higher concentrations.

The spectrum acquired with $0.22 \mathrm{M}$ ammonium acetate (Figure 1a) has a low-intensity charge-state distribution consisting of broad peaks that correspond to the mass of the hexamer. The high baseline from $\mathrm{m} / \mathrm{z}$ 2000 to $\sim 6000$ may obscure a relatively low signal corresponding to the monomer, while the dimer is

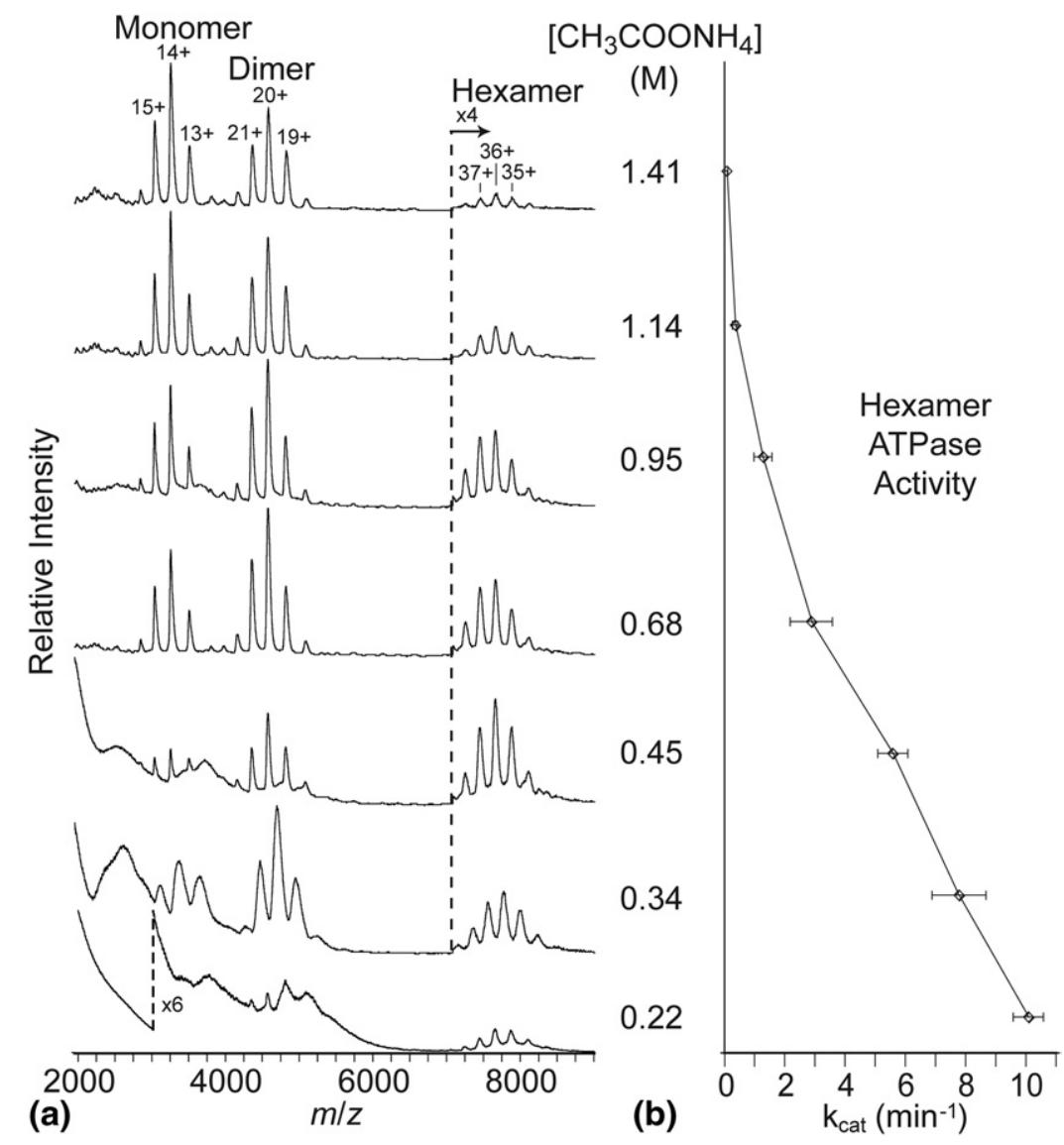

Figure 1. The effect of ammonium acetate concentration on the abundance of the hexameric oligomer of NtrC4-RC assembled in the presence of millimolar concentrations of $\mathrm{MgCl}_{2}, \mathrm{NaF}, \mathrm{BeCl}_{2}$ and $\mathrm{ADP}$ measured at $63{ }^{\circ} \mathrm{C}$ by (a) nanoESI mass spectrometry and (b) ATPase activity, which is related to the concentration of the hexamer of NtrC4-RC in solution. $\mathrm{k}_{\text {cat }}$ is calculated as moles of ATP hydrolyzed per mole of protein per minute. 
partially resolved with four charge states that have increasing peak widths with decreasing charge state. At $0.34 \mathrm{M}$ ammonium acetate, charge-state distributions of both the monomer and dimer are clearly observed, albeit with very broad peaks (Table 1 ). The broad baseline below $m / z 6000$ decreases with increasing ammonium acetate concentration and is essentially flat at concentrations $\geq 0.68 \mathrm{M}$. In addition, there is a significant shift of the centroids of all of the peaks in the three charge state distributions to higher $m / z$ at $0.34 \mathrm{M}$ ammonium acetate concentration, presumably due to salt adduction, which leads to a significant increase in ion mass (Table 1). At ammonium acetate concentrations above $0.45 \mathrm{M}$, the relative abundance of the hexamer decreases dramatically with a concomitant increase in the relative abundance of the monomer. These trends continue with ammonium acetate concentration up to $1.41 \mathrm{M}$, where the relative abundance of the hexamer is only $\sim 2 \%$ and that of the monomer is $\sim 59 \%$ (Table 1 ). In comparison, the relative abundances of the hexamer and monomer at $0.45 \mathrm{M}$, the lowest concentration at which signal is reproducible, are $\sim 22 \%$ and $\sim 23 \%$, respectively. At all concentrations of ammonium acetate, the experimental masses for monomer, dimer, and hexamer are higher than the theoretical molecular weights listed in Table 1, which were calculated from the known amino acid sequence of the NtrC4-RC protein. The mass of the unactivated monomer measured without essential salts or heat $(44.9 \mathrm{kDa})$ is lower than that measured for the monomer from activated, heated solutions, indicating significant association with $\mathrm{BeF}_{3}{ }^{-}$and $\mathrm{ADP}$ in the ESI solution and non-specific adduction of $\mathrm{Mg}^{+}$and/or $\mathrm{Cl}^{-}$[29]. No signal for other oligomers was observed. The dramatic increase in the relative abundance of monomer as a function of ammonium acetate concentration is consistent with interference of the hexamer assembly pathway rather than a decrease of hexamer due to nonspecific aggregation or other loss channels.

Ionic strength is well known as a factor in the stability of biomolecules, and high concentrations of ammonium acetate have been used to specifically reduce the binding affinities of protein complexes [3, 33]. To corroborate that the observed decrease in signal-tonoise of the hexamer from solutions with the highest concentrations of ammonium acetate occurs in solution before the ESI process, ATPase activity was measured in an independent assay [30] to determine the abundance of active hexamer in solution. The NtrC4 catalytic site for ATP hydrolysis is formed by interdomain contacts that exist only in the hexamer [28, 34, 35], so a change in the rate of ATP hydrolysis can be used to indicate the relative concentration of active hexamer in solution. The decrease in ATP hydrolysis with increasing ammonium acetate concentration (Figure $1 \mathrm{~b}$ ) is concomitant with the decrease in the relative abundance of the hexamer, and increase in the relative abundance of the monomer, measured by ESI-MS (Figure 1a) at the higher ammonium acetate concentrations. At the two lowest ammonium acetate concentrations, the low signal reproducibility and high baseline make it difficult to draw direct comparison with the activity assay. Nonetheless, these results are consistent with the ammonium acetate at high concentration displacing interactions between the protein and the essential salts / nucleotide, inhibiting the conformational change in the receiver domain that is required for oligomerization into the active form of the complex [29].

\section{Conclusion}

These results demonstrate that buffer loading with ammonium acetate can dramatically improve the resolution and the mass accuracy of nanoESI-MS measurements of noncovalent protein complexes that require low millimolar concentrations of nonvolatile salts and/or nucleotide to assemble into their physiologically relevant form. However, high concentrations of ammonium acetate can disrupt key interactions by displacement and/or interference of crucial electrostatic contacts that allow for assembly. Taken together, these effects provide additional evidence that within a range

Table 1. Experimental molecular weights (Exp. MW) and mean peak widths (full width at half-maximum) for the example spectra shown in Figure 1a, and mean relative abundances (Rel. abun.) from the three replicate measurements taken at each ammonium acetate concentration

\begin{tabular}{|c|c|c|c|c|c|c|c|c|c|}
\hline \multirow[b]{2}{*}{$\begin{array}{l}\text { [Ammonium } \\
\text { acetate] (M) }\end{array}$} & \multicolumn{3}{|c|}{ Monomer (44,929 Da) } & \multicolumn{3}{|c|}{ Dimer $(89,858 \mathrm{Da})$} & \multicolumn{3}{|c|}{ Hexamer* $(269,574 \mathrm{Da})$} \\
\hline & $\begin{array}{l}\text { Exp. MW } \\
\text { (Da) }\end{array}$ & $\begin{array}{c}\text { Mean } \\
\text { FWHM } \\
(m / z)\end{array}$ & $\begin{array}{c}\text { Rel. } \\
\text { abun. } \\
(\%)\end{array}$ & $\begin{array}{l}\text { Exp. MW } \\
\text { (Da) }\end{array}$ & $\begin{array}{l}\text { Mean } \\
\text { FWHM } \\
(m / z)\end{array}$ & $\begin{array}{l}\text { Rel. } \\
\text { abun. } \\
(\%)\end{array}$ & $\begin{array}{l}\text { Exp. MW } \\
\text { (Da) }\end{array}$ & $\begin{array}{c}\text { Mean } \\
\text { FWHM } \\
(m / z)\end{array}$ & $\begin{array}{l}\text { Rel. } \\
\text { abun. } \\
(\%)\end{array}$ \\
\hline 1.41 & $45,623 \pm 39$ & $47 \pm 6$ & $59 \pm 7$ & $91,685 \pm 15$ & $60 \pm 4$ & $39 \pm 6$ & $272,227 \pm 74$ & $70 \pm 6$ & $2 \pm 1$ \\
\hline 1.14 & $45,585 \pm 8$ & $45 \pm 4$ & $48 \pm 1$ & $91,566 \pm 28$ & $56 \pm 4$ & $48 \pm 1$ & $271,967 \pm 104$ & $71 \pm 4$ & $3 \pm 2$ \\
\hline 0.95 & $45,552 \pm 16$ & $37 \pm 2$ & $43 \pm 4$ & $91,469 \pm 39$ & $52 \pm 3$ & $51 \pm 3$ & $272,206 \pm 92$ & $64 \pm 6$ & $5 \pm 2$ \\
\hline 0.68 & $45,614 \pm 5$ & $44 \pm 5$ & $43 \pm 8$ & $91,560 \pm 32$ & $55 \pm 1$ & $51 \pm 6$ & $271,601 \pm 59$ & $75 \pm 4$ & $6 \pm 2$ \\
\hline 0.45 & $45,587 \pm 38$ & $36 \pm 3$ & $23 \pm 9$ & $91,474 \pm 38$ & $53 \pm 7$ & $55 \pm 6$ & $271,817 \pm 92$ & $72 \pm 6$ & $22 \pm 4$ \\
\hline 0.34 & $47,129 \pm 382$ & $136 \pm 38$ & $21 \pm 7$ & $93,885 \pm 138$ & $118 \pm 7$ & $66 \pm 4$ & $274,268 \pm 214$ & $98 \pm 5$ & $13 \pm 4$ \\
\hline 0.22 & $\mathrm{~N} / \mathrm{A}$ & N/A & $\mathrm{N} / \mathrm{A}$ & $91,406 \pm 132$ & $101 \pm 62$ & $15 \pm 26$ & $271,479 \pm 158$ & $71 \pm 6$ & $85 \pm 26$ \\
\hline
\end{tabular}

* Experimental molecular weights are corrected with the method of McKay et al. [32]. Errors for both experimental molecular weight and mean FWHM are reported as one standard deviation from the mass spectra shown in Figure 1. Errors in relative abundance correspond to one standard deviation in the three replicate measurements. 
of suitable solution conditions, including temperature and ionic strength, ESI-MS can be invaluable for obtaining stoichiometric and thermodynamic information about macromolecular complexes.

\section{Acknowledgments}

The authors acknowledge generous financial support from the National Institutes of Health (E.R.W.: R01-GM064712-08) and (D.E.W.: R01-GM062163).

\section{References}

1. Sharon, M.; Robinson, C. V. The Role of Mass Spectrometry in Structure Elucidation of Dynamic Protein Complexes. Annu. Rev. Biochem. 2007, 76, 167-193.

2. Wang, L. T.; Lane, L. C.; Smith, D. L. Detecting Structural Changes in Viral Capsids by Hydrogen Exchange and Mass Spectrometry. Protein Sci. 2001, 10, 1234-1243.

3. Kapur, A.; Beck, J. L.; Brown, S. E.; Dixon, N. E.; Sheil, M. M. Use of Electrospray Ionization Mass Spectrometry to Study Binding Interactions Between a Replication Terminator Protein and DNA. Protein Sci. 2002, 11, 147-157.

4. Krishnaswamy, S. R.; Williams, E. R.; Kirsch, J. F. Free Energies of Protein-Protein Association Determined by Electrospray Ionization Mass Spectrometry Correlate Accurately with Values Obtained by Solution Methods. Protein Sci. 2006, 15, 1465-1475.

5. Daneshfar, R.; Kitova, E. N.; Klassen, J. S. Determination of ProteinLigand Association Thermochemistry Using Variable-Temperature Nanoelectrospray Mass Spectrometry. J. Am. Chem. Soc. 2004, 126, 4786-4787.

6. van Duijn, E.; Simmons, D. A.; van den Heuvel, R. H. H.; Bakkes, P. J.; van Heerikhuizen, H.; Heeren, R. M. A.; Robinson, C. V.; van der Vies, S. M.; Heck, A. J. R. Tandem Mass Spectrometry of Intact GroELSubstrate Complexes Reveals Substrate-Specific Conformational Changes in the Trans Ring. J. Am. Chem. Soc. 2006, 128, 4694-4702.

7. Fandrich, M.; Tito, M. A.; Leroux, M. R.; Rostom, A. A.; Hartl, F. U.; Dobson, C. M.; Robinson, C. V. Observation of the Noncovalent Assembly and Disassembly Pathways of the Chaperone Complex MtGimC by Mass Spectrometry. Proc. Natl. Acad. Sci. U.S.A. 2000, 97, 14151-14155.

8. Hernandez, H.; Robinson, C. V. Determining the Stoichiometry and Interactions of Macromolecular Assemblies from Mass Spectrometry. Nat. Protoc. 2007, 2, 715-726.

9. Bishop, G. R.; Davidson, V. L. Catalytic Role of Monovalent Cations in the Mechanism of Proton Transfer which Gates an Interprotein Electron Transfer Reaction. Biochemistry 1997, 36, 13586-13592.

10. Chi, C. N.; Engstrom, A.; Gianni, S.; Larsson, M.; Jemth, P. Two Conserved Residues Govern the Salt and $\mathrm{pH}$ Dependencies of the Binding Reaction of a PDZ Domain. J. Biol. Chem. 2006, 281, 3681136818 .

11. Hiasa, H.; Shea, M. E.; Richardson, C. M.; Gwynn, M. N. Staphylococcus aureus Gyrase-Quinolone-DNA Ternary Complexes Fail to Arrest Replication Fork Progression In Vitro-Effects of Salt on the DNA Binding Mode and the Catalytic Activity of S. aureus Gyrase. J. Biol. Chem. 2003, 278, 8861-8868

12. Padua, R. A.; Nagy, J. I.; Geiger, J. D. Ionic-Strength Dependence of Calcium, Adenine-Nucleotide, Magnesium, and Caffeine Actions on Ryanodine Receptors in Rat Brain. J. Neurochem. 1994, 62, 2340-2348.

13. Waas, W. F.; Dalby, K. N. Physiologic Concentrations of Divalent Magnesium Ion Activate the Serine/Threonine Specific Protein Kinase ERK2. Biochemistry 2003, 42, 2960-2970.

14. Salhany, J. M.; Sloan, R. L.; Cordes, K. S. The Carboxyl Side Chain of Glutamate 681 Interacts with a Chloride Binding Modifier Site that Allosterically Modulates the Dimeric Conformational State of Band 3 (AE1). Implications for the Mechanism of Anion/Proton Cotransport. Biochemistry 2003, 42, 1589-1602.
15. Fedosova, N. U.; Esmann, M. Nucleotide-Binding Kinetics of $\mathrm{Na}, \mathrm{K}-$ ATPase: Cation Dependence. Biochemistry 2004, 43, 4212-4218.

16. Jackson, A. U.; Talaty, N.; Cooks, R. G.; Van Berkel, G. J. Salt Tolerance of Desorption Electrospray Ionization (DESI). J. Am. Soc. Mass Spectrom. 2007, 18, 2218-2225.

17. McDonnell, L. A.; Heeren, R. M. A. Imaging Mass Spectrometry. Mass Spectrom. Rev. 2007, 26, 606-643.

18. Pan, J. X.; Xu, K.; Yang, X. D.; Choy, W. Y.; Konermann, L. SolutionPhase Chelators for Suppressing Nonspecific Protein-Metal Interactions in Electrospray Mass Spectrometry. Anal. Chem. 2009, 81, 5008-5015.

19. de Boer, A. R.; Letzel, T.; Lingeman, H.; Irth, H. Systematic Development of an Enzymatic Phosphorylation Assay Compatible with Mass Spectrometric Detection. Anal. Bioanal. Chem. 2005, 381, 647-655.

20. Iavarone, A. T.; Udekwu, O. A.; Williams, E. R. Buffer Loading for Counteracting Metal Salt-Induced Signal Suppression in Electrospray Ionization. Anal. Chem. 2004, 76, 3944-3950.

21. Watt, S. J.; Urathamakul, T.; Schaeffer, P. M.; Williams, N. K.; Sheil M. M.; Dixon, N. E.; Beck, J. L. Multiple Oligomeric Forms of Escherichia coli DnaB Helicase Revealed by Electrospray Ionization Mass Spectrometry. Rapid Commun. Mass Spectrom. 2007, 21, 132-140.

22. Siezen, R. J.; Bindels, J. G.; Hoenders, H. J. The Quaternary Structure of Bovine Alpha-Crystallin-Effects of Variation in Alkaline pH, IonicStrength, Temperature. Eur. J. Biochem. 1980, 111, 435-444.

23. Brenowitz, M.; Bonaventura, C.; Bonaventura, J. Assembly and CalciumInduced Cooperativity of Limulus-IV Hemocyanin-a Model System for Analysis of Structure-Function Relationships in the Absence of Subunit Heterogeneity. Biochemistry 1983, 22, 4707-4713.

24. Wagner, R.; Gonzalez, D. H.; Podesta, F. E.; Andreo, C. S. Changes in the Quaternary Structure of Phosphoenolpyruvate Carboxylase Induced by Ionic-Strength Affect Its Catalytic Activity. Eur. J. Biochem. 1987, 164, 661-666.

25. Valero, E.; Debonis, S.; Filhol, O.; Wade, R. H.; Langowski, J.; Chambaz, E. M.; Cochet, C. Quaternary Structure of Casein Kinase-2 Characterization of Multiple Oligomeric States and Relation with Its Catalytic Activity. J. Biol. Chem. 1995, 270, 8345-8352.

26. Smith, S. P.; Barber, K. R.; Dunn, S. D.; Shaw, G. S. Structural Influence of Cation Binding to Recombinant Human Brain S100b: Evidence for Calcium-Induced Exposure of a Hydrophobic Surface. Biochemistry 1996, 35, 8805-8814.

27. Bertenshaw, G. P.; Norcum, M. T.; Bond, J. S. Structure of Homo- and Hetero-Oligomeric Meprin Metalloproteases-Dimers, Tetramers, and High Molecular Mass Multimers. J. Biol. Chem. 2003, 278, 2522-2532.

28. Batchelor, J. D.; Doucleff, M.; Lee, C.-J.; Matsubara, K.; De Carlo, S.; Heideker, J.; Lamers, M. H.; Pelton, J. G.; Wemmer, D. E. Structure and Regulatory Mechanism of Aquifex aeolicus NtrC4: Variability and Evolution in Bacterial Transcriptional Regulation. J. Mol. Biol. 2008, 384, 1058-1075.

29. Batchelor, J. D.; Sterling, H. J.; Hong, E.; Williams, E. R.; Wemmer, D. E. Receiver Domains Control the Active-State Stoichiometry of Aquifex aeolicus $\sigma^{54}$ Activator NtrC4, as Revealed by Electrospray Ionization Mass Spectrometry. J. Mol. Biol. 2009, 393, 634-643.

30. Chen, B.; Guo, Q.; Guo, Z.; Wang, X. An Improved Activity Assay Method for Arginine Kinase Based on a Ternary Heteropolyacid System. Tsinghua Sci. Technol. 2003, 8, 422-427.

31. Sterling, H. J.; Williams, E. R. Origin of Supercharging in Electrospray Ionization of Noncovalent Complexes from Aqueous Solution. J. Am. Soc. Mass Spectrom. 2009, 20, 1933-1943.

32. McKay, A. R.; Ruotolo, B. T.; Ilag, L. L.; Robinson, C. V. Mass Measurements of Increased Accuracy Resolve Heterogeneous Populations of Intact Ribosomes. J. Am. Chem. Soc. 2006, 128, 11433-11442.

33. Zhou, M.; Sandercock, A. M.; Fraser, C. S.; Ridlova, G.; Stephens, E.; Schenauer, M. R.; Yokoi-Fong, T.; Barsky, D.; Leary, J. A.; Hershey, J. W.; Doudna, J. A.; Robinson, C. V. Mass Spectrometry Reveals Modularity and a Complete Subunit Interaction Map of the Eukaryotic Translation Factor EIF3. Proc. Natl. Acad. Sci. U.S.A. 2008, 105, 18139-18144.

34. Lee, S. Y.; Torre, A.; Yan, D.; Kustu, S.; Nixon, B. T.; Wemmer, D. E. Regulation of the Transcriptional Activator NtrC1: Structural Studies of the Regulatory and AAA+ ATPase Domains. Genes Dev. 2003, 17, 2552-2563.

35. Doucleff, M.; Chen, B.; Maris, A. E.; Wemmer, D. E.; Kondrashkina, E.; Nixon, B. T. Negative Regulation of AAA+ ATPase Assembly by Two Component Receiver Domains: A Transcription Activation Mechanism that is Conserved in Mesophilic and Extremely Hyperthermophilic Bacteria. J. Mol. Biol. 2005, 353, 242-255. 